Int Arch Allergy Immunol 1997;113:520

\title{
Subject Index, Vol. 113, 1997
}

For the Subject Index of No. 1-3, please see pp. 390-392

Acquired immunodeficiency syndrome 512

Adhesion molecules 495,512

Allergenicity 478

Anaphylactic degranulation 465

Antifibrillarin antibodies 432

Asthma 489

Atopic dermatitis 489, 495

Autoantibody 454

Autoimmunity 432

Baculovirus 409,417

Basic science review 393

Biodegradable microspheres 424

Bovine $\alpha$-lactalbumin 478

CD40 393

CD40L 393

CD45 444

Cloning 409,417

Cynomolgus monkey 417

Derfl 489

- $\quad$ f2 489

Dermatophagoidesfarinae 489 Eczema 516

Endothelial cells 495 Eosinophil 465

- $\quad$ cationic protein 505

Exercise-induced anaphylaxis 505

FceRI 444

Food allergy 505

House dust mite 489

Human immunodeficiency virus 512

$\operatorname{IgE} 444$

antibody 489 Immune activation 432

modulation 400 Immunoblotting 489 Immunomodulator 424

Integrins 495 Interleukin-2 417 Interleukin-6, caprine 409 Kaposi's sarcoma 512 Keratinocyte

495 Lactose intolerance 516 Lupus nephritis 454 Lyso-paf 460

- $\quad$ receptors 460

Mast cell 465

Methotrexate 454

MRL/lprmice 454 
Mucosal immunity 424

MX-68 454

Mycobacterial disease 400 Neutrophils, human 460 Piecemeal degranulation 465 Plateletactivating factor receptor 460 Poly-(D, L-lactide-co-glycolide) 424 Poly-(L-lactic acid) 424 Protein kinase C 460

Radioallergosorbent test 489

sCD54 512

SCD62E 512

SCD106 512

Schwann cells 400

Signal transduction 444

Silver 432

Solvent evaporation 424

- $\quad$ extraction 424

Specific human IgE binding 478 T-cell subsets 400 THP1 cell line 444 Tryptic peptides 478 Vaccine delivery system 424 Vesicular transport 465

KAHGER

E-Mail karger@karger.ch Fax+ 41613061234 http://www. karger. ch (C) 1997 S. KargerAG, Basel 